\title{
An intuitionistic fuzzy Choquet integral operator based methodology for environmental criteria integrated supplier evaluation process
}

\author{
G. Tuzkaya
}

Received: 6 July 2011/Revised: 8 November 2011/Accepted: 17 March 2012/Published online: 2 March 2013

(C) Islamic Azad University (IAU) 2013

\begin{abstract}
Supplier evaluation problems deal with selecting appropriate suppliers considering multiple criteria, which may be related with qualitative and quantitative aspects. Traditional supplier selection criteria contain criteria such as cost, capacity, delivery reliability, flexibility, and responsiveness, etc. However, due to the increasing level of environmental problems, it is a necessity to take environmental criteria into account together with the traditional decision criteria in the supplier evaluation processes of companies. Considering this necessity, this paper proposes a decision making methodology for environmental criteria integrated supplier evaluation processes. A methodology based on intuitionistic fuzzy Choquet integral operator is utilized to take into account vagueness of the decision environment and the interactions among the criteria. This methodology also provides the consideration of the satisfaction and dissatisfaction degrees of alternatives for each criterion with the help of intuitionistic fuzzy values. In addition, the effects of the criteria weights to the final ranking of suppliers are analyzed via sensitivity analyses.
\end{abstract}

Keywords Fuzzy sets - Multi-criteria decision making · Supplier selection · Sustainability

\section{Introduction}

Supplier selection is the process by which suppliers are reviewed, evaluated, and chosen to become a part of the

G. Tuzkaya ( $\varangle)$

Department of Industrial Engineering, Marmara University, Göztepe, Istanbul 34722, Turkey

e-mail: gulfem.tuzkaya@marmara.edu.tr company's supply chain (Sean 2010). The contemporary supply management is to maintain long-term partnership with suppliers, and use fewer but reliable suppliers. Therefore, choosing the right suppliers involves much more than scanning a series of price list, and choices will depend on a wide range of factors which involve both quantitative and qualitative aspects (Ho et al. 2010). Considering these factors, it can be said that supplier selection problem is a multi-criteria decision making problem which is affected by several conflicting factors (Amid et al. 2006).

Supplier selection decisions affect almost every decision of the supply chain (Biylk et al. 2005). Due to its importance for the companies' long-term success, supplier selection problem is investigated both from academicians and practitioners very often. Some of the studies which are mostly utilized while preparing this study can be summarized as follows. Ghodsypour and O'Brien (1998) presented an integrated analytical hierarchy process (AHP) and linear programming approach to consider both tangible and intangible factors in choosing the best suppliers and placing the optimum order quantities among them such that the total value of purchasing becomes maximum. Same year, de Boer et al. (1998) aimed to depict that an outranking approach may be very well suited as a decision making tool for initial purchasing decisions. Verma and Pulman (1998) examined the differences between managers' rating of the perceived importance of different supplier attributes and their actual choice of suppliers in an experimental setting. Valluri and Croson (2003) used agentbased modeling to study the performance of a supplier selection model. de Boer et al. (1998) described an experimental study for formal supplier selection decision making models focusing on all phases of the supplier selection process. Wang et al. (2004) presented a paper 
related with the product characteristics of supply chain strategy and adopted supply chain operations reference (SCOR) model using Level 1 performance metrics as their decision criteria. The authors employed an integrated AHP and preemptive goal programming based multi-criteria decision making methodology. Ozgen et al. (2008) proposed a two phase possibilistic linear programming methodology for multi-objective supplier evaluation and order allocation problem. In that study, an integration of AHP and multi-objective possibilistic linear programming technique is utilized.

A large body of study on supplier evaluation literature can be found additionally. However, Kuo et al. (2010), Weber et al. (1991), Degraeve et al. (2000), de Boer et al. (2001) are some of the most important articles on supplier selection literature and detailed information about the problem and its literature can be obtained from those articles. Considering the extensive literature on supplier selection problem, there are a few studies which evaluate suppliers from an environmental perspective (Table 1). Some of these studies can be summarized as follows.

One of the initial studies in which suppliers' environmental performance is considered prepared by Noci (1997). In that paper, a conceptual approach that identifies measures for assessing a supplier's environmental performance and some techniques for developing the supplier selection procedure according to environmental viewpoint are proposed. Handfield et al. (2002) proposed a methodology to evaluate suppliers from an environmental perspective. In that study, AHP is utilized as a decision making tool. Humphreys et al. (2003a) proposed a case-based reasoning methodology to evaluate suppliers' environmental performance. Also, Humphreys et al. (2003b) proposed a decision support system to integrate environmental criteria to supplier selection process. Lu et al. (2007) presented an innovative method using simple and efficient procedures to evaluate the effectiveness of projects supplying green supply chain concept. Specifically, a multi-criteria decision making process for green supply chain management is presented to help the supply chain manager in measuring and evaluating suppliers' performance based on AHP decision making method (Lu et al. 2007). Lee et al. (2009) emphasized that while the works on the evaluation and/or selection of suppliers are abundant, those that concern environmental issues are rather limited. In their study, a model for evaluating traditional suppliers and green suppliers is proposed. First, the Delphi method is applied to differentiate the criteria for evaluating traditional suppliers and green suppliers. Then, fuzzy AHP is utilized to evaluate the importance of criteria of the selected criteria and the performance of green suppliers (Lee et al. 2009). Bai and Sarkis (2010) stated that green supplier development is necessary for effective green supply chain management and they proposed a rough set theory approach to investigate the relationships between organizational attributes, supplier development program involvement attributes, and performance outcomes. In that study, performance outcomes focus on environmental and business dimensions (Bai and Sarkis 2010). Hsu and $\mathrm{Hu}$ (2009) proposed an analytic network process (ANP) approach to incorporate the issue of hazardous substance management into supplier selection process (Hsu and $\mathrm{Hu}$ 2009). Kuo et al. (2010) developed a green supplier selection model which integrates artificial neural network (ANN) and two multiattribute decision analysis (MADA) methods: data envelopment analyses (DEA) and ANP. With their methodology, they considered both traditional supplier selection criteria and environmental regulations (Kuo et al. 2010). Tuzkaya et al. (2009) proposed a fuzzy multi-criteria decision making (MCDM) methodology to evaluate environmental performance of suppliers. They proposed a hybrid fuzzy ANP-fuzzy PROMETHEE approach (Tuzkaya et al. 2009). With a similar study, Awasti et al. (2010) proposed a fuzzy TOPSIS methodology for the evaluation of environmental performance of suppliers. Their methodology consists of three steps: criteria determination, supplier evaluation and sensitivity analyses (Awasti et al. 2010).

Considering related literature, it can be observed that most of the studies take into account environmental criteria separate from traditional supplier selection criteria. Lee et al. (2009) and Bai and Sarkis (2010) are the studies containing integrated consideration of both environmental criteria and traditional supplier selection criteria. This integration is found necessary after interviews with decision makers from application areas from various industries. In today's business environment, ignorance of environmental criteria can not be acceptable with the increasing environmental problems. However, some other facts such as quality, cost, etc. should always be considered in the decision making processes for the sustainability of the companies.

Also, considering the difficulties in evaluation of alternatives for some of the qualitative criteria and vagueness in the values of some of the quantitative criteria, using fuzzy logic is found useful and proper. When the environmental supplier evaluation literature is investigated, the studies prepared by Humphreys et al. (2006), Lu et al. (2007), Tuzkaya et al. (2009), Lee et al. (2009), Bai and Sarkis (2010) and Awasti et al. (2010) also take into account the vagueness of this decision making environment.

In this study, an environmental criteria-integrated fuzzy supplier evaluation methodology is proposed and a methodology based on fuzzy intuitionistic Choquet integral operator is utilized as a decision making tool. When 
Table 1 Literature on environmental performance evaluation of suppliers

\begin{tabular}{|c|c|c|c|c|c|}
\hline & \multicolumn{2}{|l|}{ Criteria type } & \multirow{2}{*}{$\begin{array}{l}\text { Consideration } \\
\text { of vagueness }\end{array}$} & \multirow{2}{*}{$\begin{array}{l}\text { Consideration of } \\
\text { interdependencies } \\
\text { between criteria }\end{array}$} & \multirow[t]{2}{*}{ Utilized technique } \\
\hline & $\begin{array}{l}\text { Traditional } \\
\text { supplier } \\
\text { selection criteria }\end{array}$ & $\begin{array}{l}\text { Environmental } \\
\text { criteria }\end{array}$ & & & \\
\hline Noci (1997) & - & $\sqrt{ }$ & - & - & AHP \\
\hline Handfield et al. (2002) & - & $\sqrt{ }$ & - & - & AHP \\
\hline $\begin{array}{l}\text { Humphreys et al. } \\
\text { (2003a) }\end{array}$ & - & $\sqrt{ }$ & - & - & $\begin{array}{l}\text { Knowledge based system-decision } \\
\text { support system }\end{array}$ \\
\hline $\begin{array}{l}\text { Humphreys et al. } \\
\text { (2003b) }\end{array}$ & - & $\sqrt{ }$ & - & - & Case-based reasoning \\
\hline Humphreys et al. (2006) & - & $\sqrt{ }$ & $\sqrt{ }$ & - & Fuzzy logic \\
\hline Lu et al. (2007) & - & $\sqrt{ }$ & $\sqrt{ }$ & - & Fuzzy AHP \\
\hline Tuzkaya et al. (2009) & - & $\sqrt{ }$ & $\sqrt{ }$ & $\sqrt{ }$ & Fuzzy ANP-Fuzzy PROMETHEE \\
\hline Hsu and $\mathrm{Hu}(2009)$ & - & $\sqrt{ }$ & - & $\sqrt{ }$ & ANP \\
\hline Lee et al. (2009) & $\sqrt{ }$ & $\sqrt{ }$ & $\sqrt{ }$ & - & Fuzzy AHP \\
\hline Bai and Sarkis (2010) & $\sqrt{ }$ & $\sqrt{ }$ & $\sqrt{ }$ & - & Grey system and rough set methodologies \\
\hline Awasti et al. (2010) & - & $\sqrt{ }$ & $\sqrt{ }$ & - & Fuzzy TOPSIS \\
\hline Kuo et al. (2010) & - & $\sqrt{ }$ & - & $\sqrt{ }$ & ANN-ANP-DEA \\
\hline This study & $\sqrt{ }$ & $\sqrt{ }$ & $\sqrt{ }$ & $\sqrt{ }$ & Fuzzy intuituionistic Choquet integral \\
\hline
\end{tabular}

Table 1 and abovementioned explanations are investigated, contributions of this paper to the related literature and the application areas can be summarized as follows (1) integration of environmental criteria and traditional criteria is very rare in the literature (only Lee et al. (2009); Bai and Sarkis (2010) integrates both aspects). This paper is one of the very few studies which approach the aspect from this integrated perspective. (2) Among those studies which integrate the environmental criteria and traditional criteria, it can be said that none of them considers the interdependencies between criteria. This study considers possible interdependencies among criteria via Choquet integral operator. In the related literature, Tuzkaya et al. (2009) and $\mathrm{Hsu}$ and $\mathrm{Hu}$ (2009) investigate interdependencies among criteria with the help of ANP approach (Table 1). However, they do not take traditional supplier selection criteria into account and $\mathrm{Hsu}$ and $\mathrm{Hu}$ (2009) do not consider vagueness in the decision environment. (3) Proposed methodology may be a useful tool for the supply chain departments of the companies. Considered criteria provides a realistic evaluation process and sensitivity analyses give the opportunity to analyze results from the different point of views.

Remaining parts of this study can be summarized as follows. In the second section of the study, decision making methodology and its preliminaries are explained. In the third section, environmental sustainability criteria integrated supplier selection methodology is explained and in the last section, some conclusion remarks are given. This research has been conducted in Istanbul, Turkey during the period April 2011-July 2011.

\section{Materials and methods}

Preliminaries for intuitionistic fuzzy Choquet integral operator

Atanassov (1986, 1999) extended Zadeh's fuzzy sets (Zadeh 1965, 2005, 2008) to intuitionistic fuzzy sets (IFSs), which assign to each of their elements a membership degree and a non-membership degree under the constraint that the sum of the two degrees does not exceed one (Xu 2010). Some basic concepts on IFSs can be explained as below (Xu 2010):

Given a fixed set $C=\left\{c_{1}, c_{2}, \ldots, c_{n}\right\}$, an IFS is defined as

$A=\left\{\left\langle C_{i}, t_{A}\left(c_{i}\right), f_{A}\left(c_{i}\right)\right\rangle \mid c_{i} \in C\right\}$,

which assigns to each element $x_{i}$ a membership degree and a non-membership degree under the condition

$0 \leq t_{A}\left(c_{i}\right)+f_{A}\left(c_{i}\right) \leq 1, \quad$ for all $c_{i} \in C$.

An ordered pair is called an intuitionistic fuzzy value (IFV), if:

$t_{\alpha}\left(c_{i}\right) \in[0,1], \quad f_{\alpha}\left(c_{i}\right) \in[0,1], \quad t_{\alpha}\left(c_{i}\right)+f_{\alpha}\left(c_{i}\right) \leq 1$,

$\mathrm{Xu}$ (2010) also gave some operators of IFVs as follows:

Let $\alpha\left(c_{i}\right)=\left(t_{\alpha}\left(c_{i}\right), f_{\alpha}\left(c_{i}\right)\right)$ and $\alpha\left(c_{i}\right)=\left(t_{\alpha}\left(c_{i}\right), f_{\alpha}\left(c_{i}\right)\right)$ be two IFVs; then 
$\alpha\left(c_{i}\right) \oplus \alpha\left(c_{j}\right)=\left(t_{\alpha}\left(c_{i}\right)+t_{\alpha}\left(c_{j}\right)-t_{\alpha}\left(c_{i}\right) t_{\alpha}\left(c_{j}\right), f_{\alpha}\left(c_{i}\right) f_{\alpha}\left(c_{j}\right)\right) ;$

$\alpha\left(c_{i}\right) \otimes \alpha\left(c_{j}\right)=\left(t_{\alpha}\left(c_{i}\right) t_{\alpha}\left(c_{j}\right), f_{\alpha}\left(c_{i}\right)+f_{\alpha}\left(c_{j}\right)-f_{\alpha}\left(c_{i}\right) f_{\alpha}\left(c_{j}\right)\right) ;$

$\lambda \alpha\left(c_{i}\right)=\left(1-\left(1-t_{\alpha}\left(c_{i}\right)^{\lambda}\right),\left(f_{\alpha}\left(c_{i}\right)\right)^{\lambda}\right), \quad \lambda>0 ;$

$\alpha\left(c_{i}\right)^{\lambda}=\left(t_{\alpha}\left(c_{i}\right)\right)^{\lambda},\left(1-\left(1-f_{\alpha}\left(c_{i}\right)^{\lambda}\right)\right), \quad \lambda>0$,

where the results are also IFVs and have the following properties:

$\alpha\left(c_{i}\right) \oplus \alpha\left(c_{j}\right)=\alpha\left(c_{j}\right) \oplus \alpha\left(c_{i}\right) ;$

$\alpha\left(c_{i}\right) \otimes \alpha\left(c_{j}\right)=\alpha\left(c_{j}\right) \otimes \alpha\left(c_{i}\right) ;$

$\lambda\left(\alpha\left(c_{i}\right) \oplus \alpha\left(c_{j}\right)\right)=\lambda \alpha\left(c_{i}\right) \oplus \lambda \alpha\left(c_{j}\right), \quad \lambda>0 ;$

$\left(\alpha\left(c_{i}\right) \otimes \alpha\left(c_{j}\right)\right)^{\lambda}=\left(\alpha\left(c_{i}\right)\right)^{\lambda} \otimes\left(\alpha\left(c_{j}\right)\right)^{\lambda}, \quad \lambda>0 ;$

$\left(\lambda_{1}+\lambda_{2}\right) \alpha\left(c_{i}\right)=\lambda_{1} \alpha\left(c_{i}\right) \oplus \lambda_{2} \alpha\left(c_{i}\right), \quad \lambda_{1}, \lambda_{2}>0 ;$

$\left(\alpha\left(c_{i}\right)\right)^{\left(\lambda_{1}+\lambda_{2}\right)}=\left(\alpha\left(c_{i}\right)\right)^{\lambda_{1}} \otimes\left(\alpha\left(c_{i}\right)\right) \lambda_{2}, \quad \lambda_{1}, \lambda_{2}>0$.

For every two intuitionistic fuzzy values A and B, the following operations and relations are valid (Tan and Chen 2010):

(1) $\alpha\left(c_{i}\right)=\alpha\left(c_{j}\right)$ if and only if $t_{\alpha}\left(c_{i}\right)=t_{\alpha}\left(c_{j}\right)$ and $f_{\alpha}\left(c_{i}\right)=f_{\alpha}\left(c_{j}\right)$ for all $c \in C$;

(2) $\quad \alpha\left(c_{i}\right) \leq \alpha\left(c_{j}\right)$ if and only if $t_{\alpha}\left(c_{i}\right) \prec=t_{\alpha}\left(c_{j}\right)$ and $f_{\alpha}\left(c_{i}\right) \geq f_{\alpha}\left(c_{j}\right)$ for all $c \in C$.

However, Eq. (15) is not satisfied in some situations. So it cannot be used to compare intuitionistic fuzzy values (Tan and Chen 2010). In such situations, score degree of IFV proposed by Chen and Tan (1994) and accuracy degree of IFV proposed by Hong and Choi (2010) can be used for the comparison. Xu (2010) explained this comparison method as follows:

Let $\alpha\left(c_{i}\right)=\left(t_{\alpha}\left(c_{i}\right), f_{\alpha}\left(c_{i}\right)\right)$ and $\alpha\left(c_{j}\right)=\left(t_{\alpha}\left(c_{j}\right), f_{\alpha}\left(c_{j}\right)\right)$ be two IFVs, $s\left(\alpha\left(x_{i}\right)\right)=t_{\alpha}\left(x_{i}\right)-f_{\alpha}\left(x_{i}\right)$ and $s\left(\alpha\left(c_{j}\right)\right)=t_{\alpha}\left(c_{j}\right)-$ $f_{\alpha}\left(c_{j}\right)$ be the scores of $\alpha\left(c_{i}\right)$ and $\alpha\left(c_{j}\right)$, respectively, and let $h\left(\alpha\left(c_{i}\right)\right)=t_{\alpha}\left(c_{i}\right)+f_{\alpha}\left(c_{i}\right)$ and $h\left(\alpha\left(c_{j}\right)\right)=t_{\alpha}\left(c_{j}\right)+f_{\alpha}\left(c_{j}\right)$ be the accuracy degrees of $\alpha\left(c_{i}\right)$ and $\alpha\left(c_{j}\right)$, respectively; then

- If $s\left(\alpha\left(c_{i}\right)\right)<s\left(\alpha\left(c_{j}\right)\right)$, then $\alpha\left(c_{i}\right)$ is smaller than $\alpha\left(c_{j}\right)$, denoted by $\alpha\left(c_{i}\right)<\alpha\left(c_{j}\right)$;

- If $s\left(\alpha\left(c_{i}\right)\right)=s\left(\alpha\left(c_{j}\right)\right)$, then

If $h\left(\alpha\left(c_{i}\right)\right)=h\left(\alpha\left(c_{j}\right)\right)$, then $\alpha\left(c_{i}\right)$ and $\alpha\left(c_{j}\right)$ represent the same information, i.e. $t_{\alpha}\left(c_{i}\right)=t_{\alpha}\left(c_{j}\right)$ and $f_{\alpha}\left(c_{i}\right)=f_{\alpha}\left(c_{j}\right)$, denoted by $\alpha\left(c_{i}\right)=\alpha\left(c_{j}\right)$;
If $h\left(\alpha\left(c_{i}\right)\right)<h\left(\alpha\left(c_{j}\right)\right)$, then $\alpha\left(c_{i}\right)$ is smaller than $\alpha\left(c_{j}\right)$, denoted by $\alpha\left(c_{i}\right)<\alpha\left(c_{j}\right)$.

As Xu and Xia (2011) stated many aggregation operators for IFSs have been developed in which the weights of the corresponding elements are independent (Xu and Xia 2011). However, for the real decision making problems, most criteria have interdependent or interactive characteristics so that it is not suitable to aggregate them by traditional aggregation operators based on additive measures (Tan and Chen 2010). In such situations, Choquet integral is a useful and interesting way to deal with this issue $(\mathrm{Xu}$ and Xia 2011). This operator not only considers the importance of the elements or their ordered positions, but also can reflect the correlations among elements or their ordered positions (Xu 2010). For this feature of Choquet integral, a well-known example from the literature can be given (Xu 2010; Grabisch 1995; Torra 2003): “A set of students is to be evaluated in relation to three subjects: \{mathematics, physics, literature\}, more importance to science-related subjects is wanted to be given than to literature, but on the other hand some advantage is wanted to be given to students that are good both in literature and in any of the science-related subjects." In such cases, correlation between decision criteria can be taken into account in the decision process via the Choquet integral. Also, as Choquet stated, Choquet integral is a very useful way of measuring the expected utility of an uncertain event (Choquet 1953).

Until now, Choquet integral has been applied to various decision problems like job-shop scheduling problems (Saad et al. 2008), intranet web-sites evaluations (Tzeng et al. 2005), 4PL operating models evaluation (Büyüközkan et al. 1999), software development risk assessment (Büyüközkan and Ruan 2010), warehouse location selection (Demirel et al. 2010), customer service perception evaluation ( $\mathrm{Hu}$ and Chen 2010), supply chain partner selection (Ashayeri et al. 2012), etc. Details and the basic concepts of the Choquet integral can be obtained from (Choquet 1953; Grabisch 1997; Marichal and Roubens 2000; Torra and Narukawa 2007).

\section{Decision making methodology}

In this paper, a methodology is proposed for supplier evaluation process which considers both environmental criteria and traditional supplier evaluation criteria. This methodology consists of several steps starting from determination of decision makers (DMs) and ending with evaluation of results (Fig. 1).

For the supplier evaluation phase, intuitionistic fuzzy Choquet integral operator for the MCDM process is utilized as can be seen from Fig. 1. Recently, Xu (2010), Tan 
and Chen (2010) proposed some intuitionistic fuzzy aggregation operators based on Choquet integral (Ashayeri et al. 2012). In this study, one of the aggregation operators introduced in these two papers is utilized. Intuitionistic fuzzy Choquet integral operator-based methodology can be summarized as follows (Tan and Chen 2010; Ashayeri et al. 2012):

Consider a multi-criteria decision problem with the set of alternatives $A=\left(a_{1}, a_{2}, \ldots, a_{m}\right)$ and set of criteria $C=\left(c_{1}\right.$, $\left.c_{2}, \ldots, c_{n}\right)$. Assume that with respect to criteria $c_{j}(j=1$, $2, \ldots, n)$, the alternative $a_{i}(i=1,2, \ldots, m)$ performance is measured by intuitionistic fuzzy values $\alpha_{a i}\left(c_{j}\right)=\left(t_{\alpha_{a_{i}}}\left(c_{j}\right)\right.$, $\left.f_{\alpha_{a_{i}}}\left(c_{j}\right)\right) \quad(i=1,2, \ldots, m) ; \quad(j=1,2, \ldots, n)$ where $t_{\alpha_{a_{j}}}\left(c_{j}\right)$ indicates the degree that the alternative $a_{i}$ satisfies the criteria $c_{j} . f_{\alpha_{a_{i}}}\left(c_{j}\right)$ indicates the degree that the alternative $a_{i}$ does not satisfy the criteria $c_{j}$, and $0 \leq t_{\alpha_{a_{i}}}\left(c_{j}\right) \leq 1$, $0 \leq f_{\alpha_{a_{i}}}\left(c_{j}\right) \leq 1, \quad t_{\alpha_{a_{i}}}\left(c_{j}\right)+f_{\alpha_{a_{i}}}\left(c_{j}\right) \leq 1$. The characteristics of the alternatives $a_{i}(i=1,2, \ldots, m)$ are represented by the intuitionistic fuzzy values (Tan and Chen 2010):

$a_{i}=\left\{\left(t_{\alpha_{a_{i}}}\left(c_{1}\right), f_{\alpha_{a_{i}}}\left(c_{1}\right)\right), \quad\left(t_{\alpha_{a_{i}}}\left(c_{2}\right), f_{\alpha_{a_{i}}}\left(c_{2}\right)\right), \ldots,\left(t_{\alpha_{a_{i}}}\left(c_{n}\right), f_{\alpha_{a_{i}}}\left(c_{n}\right)\right)\right\}$

The basic steps of the multi-criteria decision making methodology with intuitionistic fuzzy Choquet integral operator is given as below (Tan and Chen 2010).

Step 1. With respect to criteria $c_{j}(j=1,2, \ldots, n)$, the partial evaluation of the alternative $a_{i}(i=1,2, \ldots, m)$ is made by an intuitionistic fuzzy value
Fig. 1 Decision making methodology

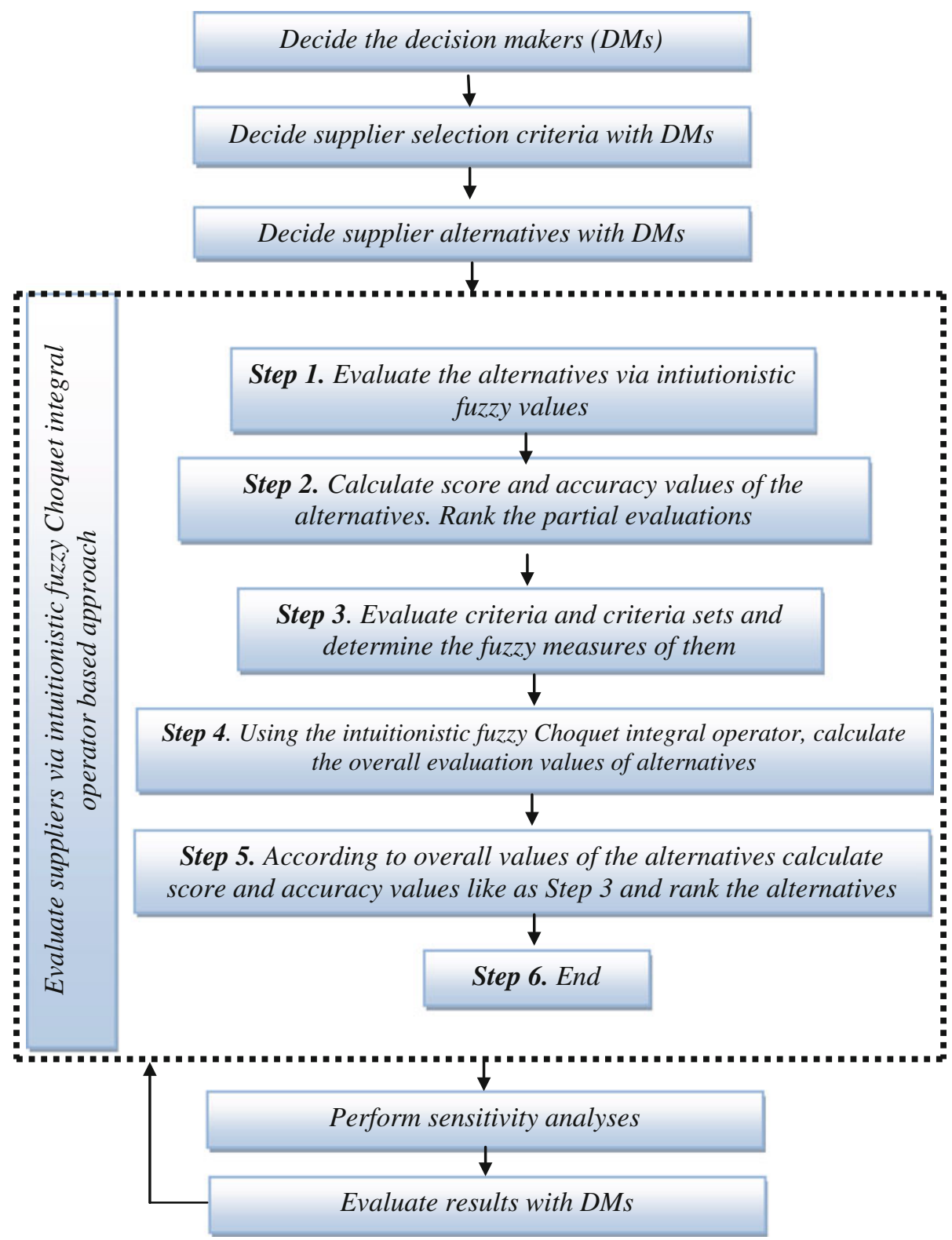


$\alpha_{a_{i}}\left(c_{j}\right)=\left(t_{\alpha_{a_{i}}}\left(c_{j}\right), f_{\alpha_{a_{i}}}\left(c_{j}\right)\right) \quad(i=1,2, \ldots, m) ;$

$(j=1,2, \ldots, n)$.

Then, a decision matrix as follows can be obtained:

$$
R=\left(\begin{array}{cccc}
\alpha_{a_{1}}\left(c_{1}\right), & \alpha_{a_{1}}\left(c_{2}\right), & \ldots, & \alpha_{a_{1}}\left(c_{n}\right) \\
\alpha_{a_{2}}\left(c_{1}\right), & \alpha_{a_{2}}\left(c_{2}\right), & \ldots, & \alpha_{a_{2}}\left(c_{n}\right) \\
\ldots & \ldots & \ldots & \ldots \\
\alpha_{a_{3}}\left(c_{1}\right), & \alpha_{a_{3}}\left(c_{2}\right), & \ldots, & \alpha_{a_{3}}\left(c_{n}\right)
\end{array}\right)
$$

Step 2. $S_{a_{i}}\left(\alpha\left(c_{j}\right)\right)$ of the partial evaluation $\alpha_{a_{i}}\left(c_{j}\right)$ of the alternative $a_{i}(i=1,2, \ldots, m)$ is calculated, and $S_{a_{i}}\left(\alpha\left(c_{j}\right)\right)$ is utilized to rank the partial evaluation $\alpha_{a_{i}}\left(c_{j}\right)$. If there is no difference between two score functions $S_{a_{i}}\left(\alpha\left(c_{j}\right)\right)$ and $S_{a_{i}}\left(\alpha\left(c_{k}\right)\right)$, then $H_{a_{i}}\left(\alpha\left(c_{j}\right)\right)$ and $H_{a_{i}}\left(\alpha\left(c_{k}\right)\right)$ of the partial evaluation $\alpha_{a_{i}}\left(c_{j}\right)$ and $\alpha_{a_{i}}\left(c_{k}\right)$ are calculated, respectively, and utilized to rank the partial evaluation $\alpha_{a_{i}}\left(c_{j}\right)$ and $\alpha_{a_{i}}\left(c_{k}\right)$. So the partial evaluation $\alpha_{a_{i}}\left(c_{j}\right)$ of the alternative $a_{i}$ is reordered such that $\alpha_{a_{i}}\left(c_{j}\right) \leq \alpha_{a_{i}}\left(c_{j+1}\right)$.

Step 3. Evaluate criteria and criteria sets and determine the fuzzy measures of them.

Step 4. Using the intuitionistic fuzzy Choquet integral operator
This manufacturer is a medium-sized one which produces relatively cheap products. To keep their products' prices in a certain level, making long time relations with their suppliers is very important for the management. Also, management aims to produce products for European Union and supply chain effectiveness improvement is an important goal for them. The company also aims to improve its environmental performance for the new market aims.

First phase of the methodology is determining the decision makers (DMs) who will contribute to the suppliers' evaluation process. In this study, ten experts from management team and supply chain management department are selected with the help of managers and a decision making group is constituted for the evaluation of suppliers.

With the second stage, decision criteria are determined for the supplier evaluation. For this stage, all possible criteria alternatives are determined via two ways: literature investigation and expert opinions. From the literature related with supplier evaluation with environmental considerations, especially the papers prepared by Tuzkaya et al. (2008, 2009), Tuzkaya and Gülsün (2008), Nakashima et al. (2006), Tsoulfas and Pappis (2006), Lu et al.

$\operatorname{IFC}_{\mu}\left(\alpha_{a_{i}}\left(c_{1}\right), \ldots, \alpha_{a_{i}}\left(c_{n}\right)\right)=\left(1-\prod_{j=1}^{n}\left(1-t_{\tilde{a}_{i(j)}}\right)^{\mu\left(\left\{A_{j}\right\}\right)+\mu\left(\left\{A_{(j+1)}\right\}\right)}, \quad \prod_{j=1}^{n}\left(f_{\tilde{a}_{i(j)}}\right)^{\mu\left(\left\{A_{(j)}\right\}\right)+\mu\left(\left\{A_{(j+1)}\right\}\right)}\right)$

aggregate all $\alpha_{a_{i}}\left(c_{j}\right)=\left(t_{\alpha_{a_{i}}}\left(c_{j}\right), f_{\alpha_{a_{i}}}\left(c_{j}\right)\right) \quad(i=1,2, \ldots, m)$ in the $i$ th line of the intuitionistic fuzzy decision matrix into an overall values $\alpha_{a_{i}}=\left(t_{\alpha_{a_{i}}}, f_{\alpha_{a_{i}}}\right)=\operatorname{IFC}_{\mu}\left(\alpha_{a_{i}}\left(c_{1}\right), \ldots, \alpha_{a_{i}}\right.$ $\left.\left(c_{n}\right)\right) \quad(i=1,2, \ldots, m)$ of the alternatives $a_{i}$, where $A_{(j)}=$ $(j, \ldots, n), A_{(n+1)}=\phi$.

Step 5. According to the overall values $\alpha_{a_{i}}=\left(t_{\alpha_{a_{i}}}, f_{\alpha_{a_{i}}}\right)$ of the alternatives $a_{i}(i=1,2, \ldots, m)$, the score function $S\left(\alpha_{a_{i}}\right)$ or the accuracy degree $H\left(\alpha_{a_{i}}\right)$ is calculated to rank the alternative $a_{i}(i=1,2, \ldots, m)$, which is similar to that of Step 3, then to select the best one.

Step 6. End.

For detailed information on intuitionistic fuzzy Choquet integral operator, see Xu (2010), and Tan and Chen (2010).

\section{Results and discussion}

Environmental criteria integrated supplier evaluation process

An application is performed to show the effectiveness of the methodology in an electronic appliances manufacturer.
(2007), and Lee et al. (2009) are utilized. From the literature related with supplier evaluation with traditional criteria, Wang et al. (2004) is utilized which uses SCOR Level 1 performance metrics (SCOR 8.0). The criteria alternatives are proposed to the experts constituted of academicians and practitioners. Initially, they are requested to propose additional criteria alternatives. With the additional alternatives, they are asked to evaluate all the criteria alternatives. Criteria alternatives and expert opinions are proposed to the DMs and mostly preferred composition is summarized as in Fig. 2.

In the next stage, DMs decide the supplier alternatives. Considering all possible supplier alternatives, five of them $\left(S_{1}-S_{2}-S_{3}-S_{4}-S_{5}\right)$ found proper by DMs for the evaluation. After deciding supplier alternatives, intuitionistic fuzzy Choquet integral-based approach is applied for the evaluation.

Next stage is the supplier evaluation stage considering each criterion. For this stage, ten experts (DMs), who are determined in the first stage of the methodology, are asked to evaluate supplier alternatives' performances. Evaluation process is realized via telephone or face to face interviews. After these interviews, expert opinions are integrated like 
as the following example. If six of the DMs think that $S_{1}$ is strong for criteria group $C_{1}$, two of DMs think that $S_{1}$ is weak for criteria group $C_{1}$, and two of DMs do not judge this alternative for the criteria group $C_{1}$, its IFV can be expressed as $(0.6,0.2)$. After DMs evaluations are realized for all alternatives and all criteria, intuitionistic fuzzy decision matrix is obtained as Table 2 (Step 1).

Supplier evaluations represented via IFVs shown in Table 2 are rearranged in ascending order via the rules explained in Sect. 2 (Step 2). Before rearranging stage, score and accuracy degrees are calculated (Table 3).

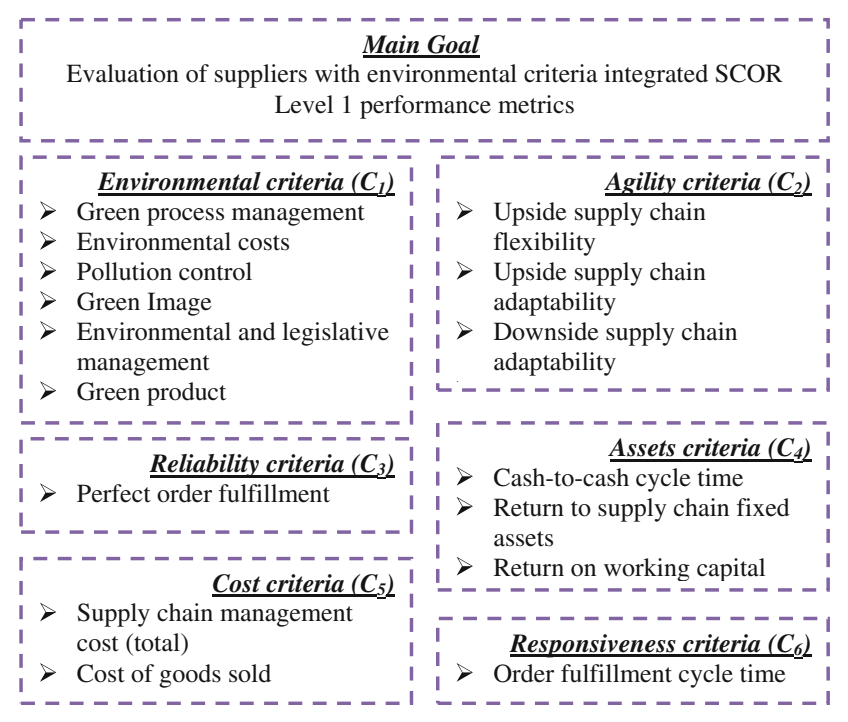

Fig. 2 Environmental criteria integrated supplier evaluation criteria

Table 2 Intuitionistic fuzzy decision matrix for supplier alternatives

\begin{tabular}{llllll}
\hline & $S_{1}$ & $S_{2}$ & $S_{3}$ & $S_{4}$ & $S_{5}$ \\
\hline$C_{1}$ & $(0.6,0.2)$ & $(0.5,0.3)$ & $(0.9,0.1)$ & $(0.6,0.2)$ & $(0.5,0.3)$ \\
$C_{2}$ & $(0.8,0.1)$ & $(0.2,0.5)$ & $(0.5,0.5)$ & $(0.7,0.2)$ & $(0.5,0.4)$ \\
$C_{3}$ & $(0.5,0.3)$ & $(0.5,0.4)$ & $(0.5,0.3)$ & $(0.5,0.5)$ & $(0.9,0.1)$ \\
$C_{4}$ & $(0.5,0.4)$ & $(0.3,0.4)$ & $(0.6,0.2)$ & $(0.5,0.4)$ & $(0.8,0.1)$ \\
$C_{5}$ & $(0.6,0.3)$ & $(0.6,0.2)$ & $(0.7,0.1)$ & $(0.5,0.3)$ & $(0.6,0.2)$ \\
$C_{6}$ & $(0.4,0.1)$ & $(0.5,0.5)$ & $(0.5,0.4)$ & $(0.9,0.1)$ & $(0.6,0.2)$ \\
\hline
\end{tabular}

Supplier evaluations in ascending order can be seen from Table 4.

In the next step, DMs evaluate the criteria considering their contribution to the main goal. According to the DMs judgements, fuzzy measures of each criterion and criteria set are shown in Table 5 (Step 3):

Using criteria weights, supplier evaluations, and ordered supplier evaluations, integrated supplier evaluations are obtained via intuitionistic fuzzy Choquet integral operator given in Step 4 of the methodology. Results are obtained as (0.66, 0.18), (0.50, 0.29), (0.81, 0.17), (0.76, 0.18), (0.85, 0.07 ) for $S_{1}, S_{2}, S_{3}, S_{4}$ and $S_{5}$, respectively. Obtained integrated evaluations are ordered with the same rule in Step 2 and the final order from best to the worst supplier is as follows: $S_{5}, S_{3}, S_{4}, S_{1}$, and $S_{2}$ (Step 5).

The best supplier, $S_{5}$, has the best evaluation values for $C_{3}$ and $C_{4}$ and second best evaluation values for $C_{5}$ and $C_{6}$. For $C_{1}$ and $C_{2}, S_{5}$ has relatively bad evaluation results. However, when the integrated membership values are obtained with the consideration of criteria weights, $S_{5}$ is ranked as the best supplier. Second best supplier, $S_{3}$, has very close evaluation values to the $S_{5}$ 's evaluation values. But, $S_{3}$ 's non-membership degrees are worse then $S_{5}$ 's nonmembership degrees which means the number of experts having bad opinions on $S_{3}$ are more then the number of experts having bad opinions on $S_{5}$. As can be expected, the worst supplier, $S_{2}$, has the worst evaluations for all of the criteria and its membership and non-membership degrees are the worst among the others.

Sensitivity analyses in the change of supplier evaluations (score values) with the change in the criteria weights are performed. Also, related criteria sets' fuzzy measures are changed with the change of the weight of each criterion. As examples, three of them selected and presented in Figs. 3, 4, and 5. Figure 3 presents the change in suppliers' score values with the change in weight of first criterion. As can be expected, $S_{3}$ 's score value is getting better with the change in the $C_{1}$ 's weight since this supplier has the best evaluation for the first criterion. Also, score value of $S_{4}$ is getting better with the increase in the weight of first criteria. For $S_{1}, S_{2}$, and $S_{5}$ 's evaluations, important changes

Table 3 Score and accuracy degrees of alternative suppliers

\begin{tabular}{|c|c|c|c|c|c|c|c|c|c|}
\hline \multicolumn{2}{|l|}{$S_{1}$} & \multicolumn{2}{|l|}{$S_{2}$} & \multicolumn{2}{|l|}{$S_{3}$} & \multicolumn{2}{|l|}{$S_{4}$} & \multicolumn{2}{|l|}{$S_{5}$} \\
\hline$S\left(\alpha_{S_{1}}\right)$ & $H\left(\alpha_{\mathrm{S}_{1}}\right)$ & $S\left(\alpha_{S_{2}}\right)$ & $H\left(\alpha_{S_{2}}\right)$ & $S\left(\alpha_{S_{3}}\right)$ & $H\left(\alpha_{S_{3}}\right)$ & $S\left(\alpha_{S_{4}}\right)$ & $H\left(\alpha_{S_{4}}\right)$ & $S\left(\alpha_{S_{5}}\right)$ & $H\left(\alpha_{S_{5}}\right)$ \\
\hline 0.40 & 0.80 & 0.20 & 0.80 & 0.80 & 1.00 & 0.40 & 0.80 & 0.20 & 0.80 \\
\hline 0.70 & 0.90 & -0.30 & 0.70 & 0.00 & 1.00 & 0.50 & 0.90 & 0.10 & 0.90 \\
\hline 0.20 & 0.80 & 0.10 & 0.90 & 0.20 & 0.80 & 0.00 & 1.00 & 0.80 & 1.00 \\
\hline 0.10 & 0.90 & -0.10 & 0.70 & 0.40 & 0.80 & 0.10 & 0.90 & 0.70 & 0.90 \\
\hline 0.30 & 0.90 & 0.40 & 0.80 & 0.60 & 0.80 & 0.20 & 0.80 & 0.50 & 0.70 \\
\hline 0.30 & 0.50 & 0.00 & 1.00 & 0.10 & 0.90 & 0.80 & 1.00 & 0.40 & 0.80 \\
\hline
\end{tabular}


Table 4 Supplier evaluations in ascending order

\begin{tabular}{|c|c|c|c|c|c|c|c|c|c|}
\hline & $S_{1}$ & & $S_{2}$ & & $S_{3}$ & & $S_{4}$ & & $S_{5}$ \\
\hline$\alpha_{S_{1}}\left(x_{\sigma(1)}\right)$ & $(0.5,0.4)$ & $\alpha_{S_{2}}\left(x_{\sigma(1)}\right)$ & $(0.2,0.5)$ & $\alpha_{S_{3}}\left(x_{\sigma(1)}\right)$ & $(0.5,0.5)$ & $\alpha_{S_{4}}\left(x_{\sigma(1)}\right)$ & $(0.5,0.5)$ & $\alpha_{S_{5}}\left(x_{\sigma(1)}\right)$ & $(0.5,0.4)$ \\
\hline$\alpha_{S_{1}}\left(x_{\sigma(2)}\right)$ & $(0.5,0.3)$ & $\alpha_{S_{2}}\left(x_{\sigma(2)}\right)$ & $(0.3,0.4)$ & $\alpha_{S_{3}}\left(x_{\sigma(2)}\right)$ & $(0.5,0.4)$ & $\alpha_{S_{4}}\left(x_{\sigma(2)}\right)$ & $(0.5,0.4)$ & $\alpha_{S_{5}}\left(x_{\sigma(2)}\right)$ & $(0.5,0.3)$ \\
\hline$\alpha_{S_{1}}\left(x_{\sigma(3)}\right)$ & $(0.4,0.1)$ & $\alpha_{S_{2}}\left(x_{\sigma(3)}\right)$ & $(0.5,0.5)$ & $\alpha_{S_{3}}\left(x_{\sigma(3)}\right)$ & $(0.5,0.3)$ & $\alpha_{S_{4}}\left(x_{\sigma(3)}\right)$ & $(0.5,0.3)$ & $\alpha_{S_{5}}\left(x_{\sigma(3)}\right)$ & $(0.6,0.2)$ \\
\hline$\alpha_{S_{1}}\left(x_{\sigma(4)}\right)$ & $(0.6,0.3)$ & $\alpha_{S_{2}}\left(x_{\sigma(4)}\right)$ & $(0.5,0.4)$ & $\alpha_{S_{3}}\left(x_{\sigma(4)}\right)$ & $(0.6,0.2)$ & $\alpha_{S_{4}}\left(x_{\sigma(4)}\right)$ & $(0.6,0.2)$ & $\alpha_{S_{5}}\left(x_{\sigma(4)}\right)$ & $(0.6,0.1)$ \\
\hline$\alpha_{S_{1}}\left(x_{\sigma(5)}\right)$ & $(0.6,0.2)$ & $\alpha_{S_{2}}\left(x_{\sigma(5)}\right)$ & $(0.5,0.3)$ & $\alpha_{S_{3}}\left(x_{\sigma(5)}\right)$ & $(0.7,0.1)$ & $\alpha_{S_{4}}\left(x_{\sigma(5)}\right)$ & $(0.7,0.2)$ & $\alpha_{S_{5}}\left(x_{\sigma(5)}\right)$ & $(0.8,0.1)$ \\
\hline$\alpha_{S_{1}}\left(x_{\sigma(6)}\right)$ & $(0.8,0.1)$ & $\alpha_{S_{2}}\left(x_{\sigma(6)}\right)$ & $(0.6,0.2)$ & $\alpha_{S_{3}}\left(x_{\sigma(6)}\right)$ & $(0.9,0.1)$ & $\alpha_{S_{4}}\left(x_{\sigma(6)}\right)$ & $(0.9,0.1)$ & $\alpha_{S_{5}}\left(x_{\sigma(6)}\right)$ & $(0.9,0.1)$ \\
\hline
\end{tabular}

Table 5 Fuzzy measures of each criterion and criteria set

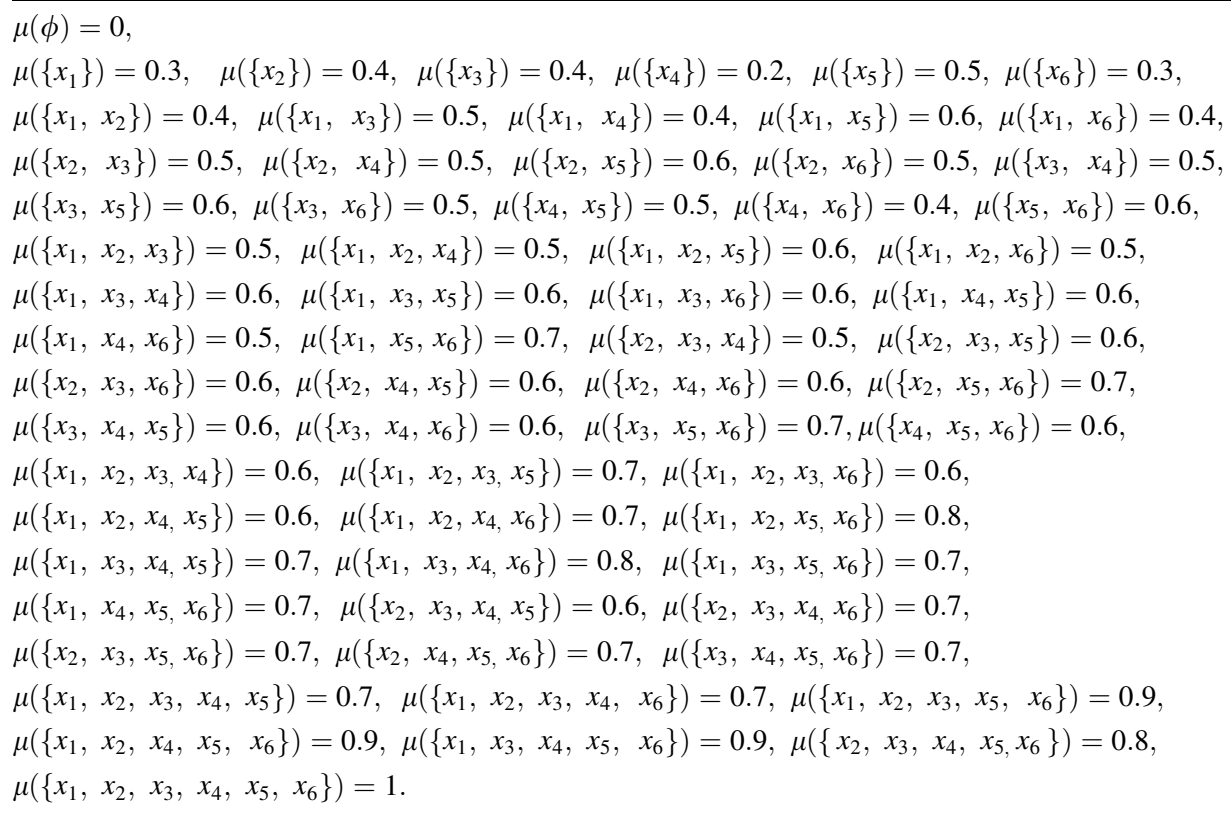

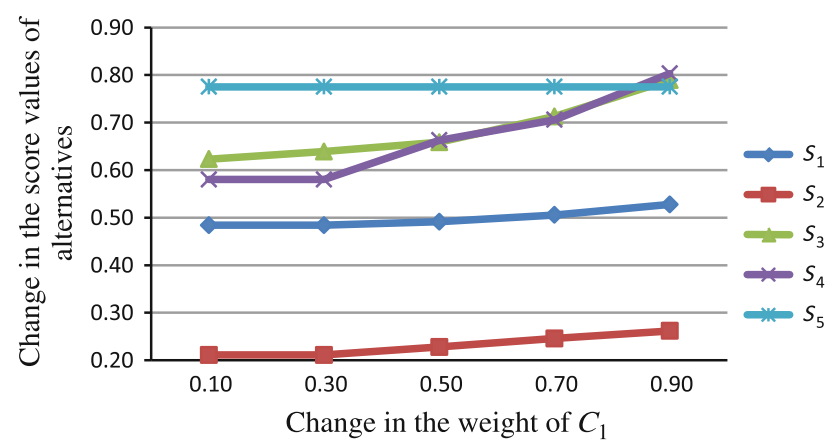

Fig. 3 Sensitivity analyses. Change in the score values of alternatives with the change in the weight of $C_{1}$

are not observed. First criterion is related with the environmental aspects, hence it can be said that with the increase in the importance degree of environmental aspects for the DMs, $S_{3}$ and $S_{4}$ 's chance of being selected would increase in a dramatic way.

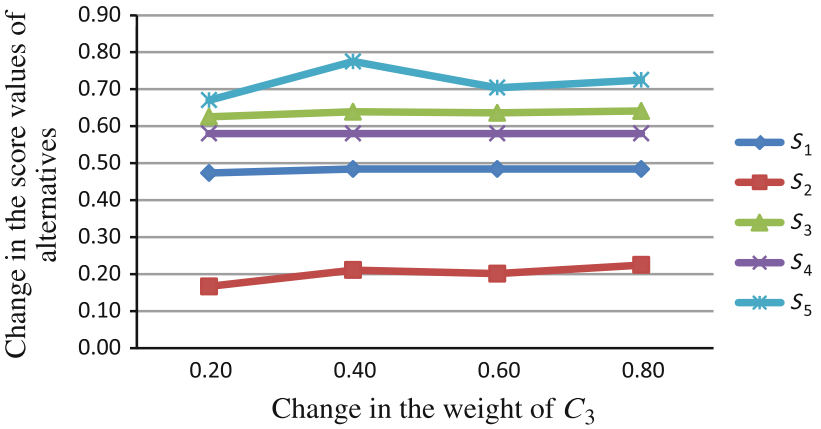

Fig. 4 Sensitivity analyses. Change in the score values of alternatives with the change in the weight of $C_{3}$

Figure 4 presents the change in suppliers' score values with the change in weight of $C_{3}$. This criterion is about the reliability of suppliers and perfect order fulfilment degrees of them. For this criterion, supplier evaluation degrees are almost same and a change in $C_{3}$ 's weight does not have an 


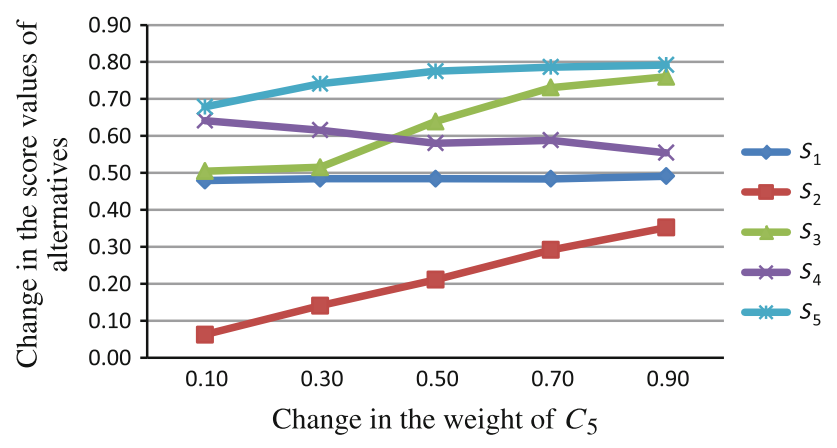

Fig. 5 Sensitivity analyses. Change in the score values of alternatives with the change in the weight of $C_{5}$

important effect on the integrated evaluations. Only, small fluctuations are observed in the score values of $S_{2}$ and $S_{5}$.

Fifth criterion is related with the cost aspects. While the weight of cost criterion is increasing, $S_{2}, S_{3}$ and $S_{5}$ 's score values are getting better. However, in the final evaluation, current order of $S_{5}$ does not change. Most dramatic change in the score values is observed in the score value of $S_{3}$ since this supplier has the best evaluation for the cost-related aspects.

\section{Conclusion}

This study proposes a supplier evaluation methodology which considers both traditional supplier selection criteria and environmental criteria. Considering the related literature, there is a large number of papers which take into account traditional supplier selection criteria like cost, capacity, flexibility, etc. can be found. Also, there are an important number of papers which evaluate suppliers from environmental point of view. However, integration of these two perspectives is very rare. Also, in this paper, vagueness inherent to decision environment is taken into account using a methodology based on intuitionistic fuzzy Choquet integral operator. This methodology allows us to take evaluations from DMs linguistically which is an easier and more proper way comparing to evaluations with certain numerical judgements. Also, synergies coming from satisfaction of certain criteria together are taken into account with the help of utilized technique. In addition, the effects of criteria weights to the decision making process is analyzed with the sensitivity analyses.

For the future researches, integration of the fuzzy intuitionistic Choquet integral operator-based methodology with another MCDM technique, like as ANP, AHP may be considered, especially for the determination of criteria and criteria sets' membership values considering their contribution to the achievement of main goal.
Acknowledgments The author is thankful to the anonymous reviewers for their valuable comments which give the opportunity to improve this paper.

\section{References}

Amid A, Godsypour SH, O’Brien C (2006) Fuzzy multiobjective linear model for supplier selection in a supply chain. Int J Prod Econ 104:394-407

Ashayeri J, Tuzkaya G, Tuzkaya UR (2012) Supply chain partners and configuration selection: an intuitionistic fuzzy Choquet integral operator based approach. Expert Syst Appl 39(3): 3642-3649

Atanassov K (1986) Intuitionistic fuzzy sets. Fuzzy Sets Syst 20:87-96

Atanassov K (1999) Intuitionistic fuzzy sets: theory and applications. Physica-Verlag, Heidelberg

Awasti A, Chauhan SS, Goyal SK (2010) A fuzzy multicriteria approach for evaluating environmental performance of suppliers. Int J Prod Econ 126:370-378

Bai C, Sarkis J (2010) Green supplier development: analytical evaluation using rough set theory. J Clean Prod 18:1200-1210

Bıyık G, Kongar E, Gülsün B (2005) A supplier selection methodology for an effective supply chain. International logistics and supply chain congress, Istanbul

Büyüközkan G, Ruan D (2010) Choquet integral based aggregation approach to software development risk assessment. Inf Sci 180(3):441-451

Büyüközkan G, Feyzioğlu O, Ersoy MŞ (1999) Evaluation of 4PL operating models: a decision making approach based on 2-additive Choquet integral. Int J Prod Econ 121:112-120

Chen SM, Tan JM (1994) Handling multicriteria fuzzy decisionmaking problems based on vague set theory. Fuzzy Sets Syst 67:163-172

Choquet G (1953) Theory of capacities. Annales de l'institut Fourier 5:131-295

de Boer L, Wegen L, Telgen J (1998) Outranking methods in support of supplier selection. Eur J Purch Supply Manag 4:109-118

de Boer L, Labro E, Morlacchi P (2001) A review of methods supporting supplier selection. Eur J Purch Supply Manag 7(2): 75-89

Degraeve Z, Labro E, Roodhooft F (2000) An evaluation of supplier selection methods from a total cost of ownership perspective. Eur J Oper Res 125(1):34-58

Demirel T, Demirel NÇ, Kahraman C (2010) Multi-criteria warehouse location selection using Choquet integral. Expert Syst Appl 37(5):3943-3952

Ghodsypour SH, O'Brien C (1998) A decision support system for supplier selection using an integrated analytic hierarchy process and linear programming. Int J Prod Econ 56-57:199-212

Grabisch M (1995) Fuzzy integral in multicriteria decision making. Fuzzy Sets Syst 69:279-298

Grabisch M (1997) K-order additive discrete fuzzy measures and their representations. Fuzzy Sets Syst 92:167-189

Handfield R, Walton SV, Sroufe R, Melnyk SA (2002) Applying environmental criteria to supplier assessment: a study in the application of the analytical hierarchy process. Eur J Oper Res 141:70-87

Ho W, Xu X, Dey PK (2010) Multi-criteria decision making approaches for supplier evaluation and selection: a literature review. Eur J Oper Res 202:16-24

Hong DJ, Choi CH (2010) Multicriteria fuzzy decision-making problems based on vague set theory. Fuzzy Sets Syst 114: $103-113$ 
Hsu C-W, Hu AH (2009) Applying hazardous substance management to supplier selection using analytical network process. J Clean Prod 17:255-264

$\mathrm{Hu}$ Y-C, Chen H-C (2010) Choquet integral-based hierarchical networks for evaluating customer service perceptions on fast food stores. Expert Syst Appl 37(12):7880-7887

Humphreys P, McIvor R, Chan F (2003a) Using case-based reasoning to evaluate supplier environmental management performance. Expert Syst Appl 25:141-153

Humphreys P, Wong YK, Chan FTS (2003b) Integrating environmental criteria into the supplier selection process. J Mater Process Technol 138(1):349-356

Humphreys P, McCloskey A, McIvor R, Maguire L, Glackin A (2006) Employing dynamic fuzzy membership functions to assess environmental performance in the supplier selection process. Int J Prod Res 44(12):2379-2419

Kuo RJ, Wang YC, Tien FC (2010) Integration of artificial neural network and MADA methods for green supplier selection. J Clean Prod 18:1161-1170

Lee AHI, Kang H-Y, Hsu C-F, Hung H-C (2009) A green supplier selection model for high-tech industry. Expert Syst Appl 36: 7917-7927

Lu LYY, Wu CH, Kuo TC (2007) Environmental principles applicable to green supplier evaluation by using multi-objective. Int J Prod Res 45(18-19):4317-4331

Marichal J-L, Roubens M (2000) Determination of weights of interacting criteria from a reference set. Eur J Oper Res 124: $641-650$

Nakashima K, Nose T, Kuriyama S (2006) A new approach to environmental performance evaluation. Int J Prod Res 44(18-19): $4137-4143$

Noci G (1997) Designing "green" vendor rating systems for the assessment of a supplier's environmental performance. Eur J Purch Supply Manag 3(2):103-114

Ozgen D, Onut S, Gulsun B, Tuzkaya UR, Tuzkaya G (2008) A twophase possibilistic linear programming methodology for multiobjective supplier evaluation and order allocation problems. Inf Sci 178(2):485-500

Saad I, Hammadi S, Benrejeb M, Borne P (2008) Choquet integral for multi criteria aggregation in the flexible job-shop scheduling problems. Math Comput Simul 76(5-6):447-462
Sean RF (2010) Restricting weights in supplier selection decisions in the presence of dual-role factors. Appl Math Model 34:2820 2830

Tan C, Chen X (2010) Intuitionistic fuzzy Choquet integral operator for multi-criteria decision making. Expert Syst Appl 37:149-157

Torra V (2003) Information fusion in data mining. Springer, Berlin

Torra V, Narukawa Y (2007) Modelling decisions-information fusion and aggregation oprators. Springer, Berlin

Tsoulfas GT, Pappis CP (2006) Environmental principles applicable to supply chain design and operation. J Clean Prod 14:1593-1602

Tuzkaya G, Gülsün B (2008) Evaluating centralized return centers in a reverse logistics network: an integrated fuzzy multi-criteria decision approach. Int J Environ Sci Technol 5(3):339-352

Tuzkaya G, Önüt S, Tuzkaya UR, Gülsün B (2008) An analytic network process approach for locating undesirable facilities: an example from Istanbul, Turkey. J Environ Manag 88(4):970-983

Tuzkaya G, Özgen A, Özgen D, Tuzkaya UR (2009) Environmental performance evaluation of suppliers: a hybrid fuzzy multi criteria decision approach. Int J Environ Sci Technol 6(3): $477-490$

Tzeng G-H, Ou Yang Y-P, Lin C-T, Chen C-B (2005) Hierarchical MADM with fuzzy integral for evaluating enterprise intranet web sites. Inf Sci 169:409-426

Valluri A, Croson DC (2003) Agent learning in supplier selection models. Decis Support Syst 39(2):219-240

Verma R, Pulman ME (1998) An analysis of the supplier selection process. Omega Int J Manag Sci 26:739-750

Wang G, Huang SH, Dismukes JP (2004) Product-driven supply chain selection using integrated multi-criteria decision making methodology. Int J Prod Econ 91(1):1-15

Weber CA, Current JR, Benton WC (1991) Vendor selection criteria and methods. Eur J Oper Res 50(1):2-18

$\mathrm{Xu} \mathrm{Z} \mathrm{(2010)} \mathrm{Choquet} \mathrm{integrals} \mathrm{of} \mathrm{weighted} \mathrm{intuitionistic} \mathrm{fuzzy}$ information. Inf Sci 180:726-736

Xu Z, Xia M (2011) Induced generalized intuitionistic fuzzy operators. Knowl Based Syst 24:197-209

Zadeh LA (1965) Fuzzy sets. Inf Control 8:338-353

Zadeh LA (2005) Toward a generalized theory of uncertainty (GTU)—an outline. Inf Sci 172:1-40

Zadeh LA (2008) Is there a need for fuzzy logic? Inf Sci 178:2751-2779 